\title{
Predictors of early re-bleeding and mortality in patients with first attack of gastric variceal hemorrhage
}

\author{
Amani M Ibrahim ${ }^{1}$, Elsayed A. Kalil ${ }^{2}$, Maha R Habeeb ${ }^{2, *}$ \\ ${ }^{1}$ Elsenblawen General Hospital, Mansoura, Egypt. ${ }^{2}$ Internal Medicine Department, Faculty of Medicine, Mansoura \\ University, Mansoura, Egypt.
}

\begin{abstract}
Background: Gastric varices (GV) bleed less frequently than esophageal varices however, gastric variceal bleeding is more severe with higher mortality and rebleeding rates. Treatment of gastric variceal bleeding (GVB) by tissue adhesive mainly cyanoacrylate glues has been used for gastric variceal obturation. We aimed to determine predictors of early rebleeding and mortality in patients with the first attack of GVB. Materials and methods: The study included 120 patients with a first attack of GVB.The patients subjected to thorough history, full examination, laboratory, and radiological investigations. Child Turcott Pugh score (CTP), and model of end stage liver disease (MELD) score were calculated. Upper gastrointestinal (GI) endoscopy with gastric variceal obturation (GVO) by cyanoacrylate glues were done for all included patients. Follow up during hospitalization and 6 weeks after discharge to determine early rebleeding (within 14 days) and early mortality (within 6 weeks). Results: Among 120 included patients in the study, 24 patients $(20 \%)$ were presented with early rebleeding and 19 patients (15.83\%) were presented with early mortality. Multi-variable logestic regression analysis showed that, Child Pugh Score was an independent prognostic factor associated with early rebleeding and early mortality. It was found that, current smoking, increased bilirubin, INR, creatinine, decreased albumin, presence of ascites, higher CTP and MELD scores are significantly more in early rebleeding and early mortality groups, while lower platelet count in early rebleeding only. Moreover, hepatic encephalopathy, and higher transaminases are more in early mortality group. There was no significant difference in gastric variceal signs between the study groups except that increase mortality in patients with more than one varix. Conclusion: Child Turcott Pugh score was an independent prognostic factor associated with early rebleeding and early mortality in patients with GVB.

\section{Introduction}

Portal hypertension is a major problem of cirrhosis and is responsible for many complications including,
\end{abstract}

Keywords: Gastric variceal bleeding, pridectorsof rebleeding, endosdopy, rebleeding, mortality

Received: 1-5-2021; Accepted: 18-6-2021

* Corresponding author. Email: maha_ragab68@yahoo.com gastrointestinal bleeding from spontaneous rupture of gastric or oesophageal varices, hepatic encephalopathy and ascites ${ }^{1-4}$. Bleeding from gastro esophageal varices is a major cause of mortality in patients with liver cirrhosis 5,6 . Isolated gastric varices (GVs), without esophageal varices (EVs), are seen in 5\%-12\% of patients with portal hypertension ${ }^{7}$. During the past decades the prognosis of esophageal variceal bleeding (EVB) has improved, however, the clinical outcome of gastric varices bleeding (GVB) is still far from excellence. GVB is more severe with higher mortality (30\%) and rebleeding (34-89\%) rates and requires more transfusions than $\mathrm{EVB}^{8,11}$.

In head-to-head studies, EVL was less effective than endoscopic obturation by injection of cyanoacrylate for hemostasis of large GVs and had higher re-bleeding rates 14,15. Trans jugular intrahepatic porto systemic shunt (TIPS) and balloon-occluded retrograde Trans venous obliteration (BRTO) are advanced radiological procedures available as salvage techniques in uncontrollable bleeding conditions or when patients are not candidates or have unsuccessful endoscopic management ${ }^{16,17}$.

The most reported risk predictors of mortality in EVB are Child-Turcotte-Pugh (CTP) score, renal failure, bacterial infection at admission or shortly after, hypovolemic shock, active bleeding at endoscopy, hepatocellular carcinoma (HCC), and hepatic venous pressure gradient above $20 \mathrm{~mm}$ $\mathrm{Hg}{ }^{18}$. Few studies focus on the clinical predictive factors of mortality for acute GVB showed that CTP score and MELD score were not significantly different in patients with GVs rebleeding; while the two scores have been extremely efficient in predicting the mortality ${ }^{19}$. However, others found that the patients with a higher level of MELD scores (above 18) had significantly more re-bleeding in comparison with the group of lower than 18 scores ${ }^{20}$. The aim of this study is to detect the possible predictors of early rebleeding within 14 days and early mortality within 6 weeks in patients with first attach of acute GVB after emergency endoscopic gastric variceal obturation.

\section{Materials and methods}

The study was carried out on one hundred and twenty patients with age ranged from (18-70 years) presented with the first attack of hematemesis and or melena due to rupture gastric varices. They were admitted to the upper gastrointestinal tract bleeding unit at the emergency hospital-Mansoura University between 2015 and 2017. 
The approval by the Mansoura medical ethics committee (MMEC) of the faculty of medicine was obtained. Informed written consent wa obtained from the patients and/or their families participated in this study after informing them about the steps of the study.

Inclusion Criteria: Patients aged 18-70 years presented by first attack gastric variceal hemorrhage either hematemesis or melena.

Exclusion Criteria: Terminal illness of any major medical problems such as (severe co-morbidities, recent myocardial infarction, cardiopulmonary instability, hypertensive shock failing to stabilize after initial resuscitation, prior to esophagogastroduodenoscopy). Causes of upper GIT bleeding other than ruptured gastric varices (oesophageal varices, cancer stomach or esophagus and portal hypertensive gastropathy). Aged below 18 years, hepatic encephalopathy grade III and IV. Patients or their first degree relatives had withdrawn their informed consent to participate in the study.

\section{All included patients in index admission were subjected to:}

History taking, full clinical examination, laboratory included, complete blood count, random blood sugar, prothrombine time and INR, AST, ALT, serum albumin and serum bilirubin, serum creatinine, anti $\mathrm{HCV}$ and $\mathrm{HBs} \mathrm{Ag}$, serum electrolytes (serum sodium and potassium), blood gases. Abdominal ultra-sound, and triphasic CT in HCC suspicious lesion.

\section{Scores calculations:}

a) Child turcott pugh (CTP) score ${ }^{21}$.

b) Model of End Stage Liver Disease (MELD) score. ${ }^{22}$.

\section{Upper GI endoscope (under midazolam sedation):}

Upper GI endoscope was done in the first 12 hours postadmission to all patients. Besides standard conservative therapy (blood transfusion, vasoactive therapy, and ceftriaxone (1 g/ 24 hours)). All endoscopic intercessions were done by very trained, equally qualified endoscopists. Endoscopic criteria of gastric varices (type5, number and size of varices ${ }^{23}$, risky signs of variceal bleeding, signs of active bleeding or recent hemorrhage). All patients were treated by GVO with isoamyl-2-cyanoacrylate.

\section{Definitions:}

Early re-bleeding was defined as: Episode withen 14 days in the form of the following:

New onset of hematemesis, coffee-ground vomitus, hematochezia, or melena, with an increasing pulse rate over 100 beats/min and decreasing blood pressure below 90 $\mathrm{mmHg}$ after a 24-hour period of stable vital signs and hemoglobin after endoscopic treatment. ${ }^{24}$
Early mortality was defined as any death occurring within 6 weeks from hospital discharge due to upper GI bleeding or hepatic mortality ${ }^{25,26}$. Renal impairment was defined when creatinine $\geq 1.5 \mathrm{mg} / \mathrm{dL} .{ }^{27}$.

\section{Statistical analysis}

Data were entered and analyzed using Statistical Packageck of Social Sciences (SPSS) software (version 21). Qualitative data were expressed as count and percent. Quantitative data were expressed as mean \pm standard deviation (SD) if normally distributed or median and interquartile range (IQR) if not. Qualitative data for two groups (2X2 table): Chi-Square test (or Fisher's exact test) was used. Qualitative data for more than two groups (e.g., 2X3 table): Chi-Square test (with Bonferroni method to adjust $\mathrm{p}$ values when comparing column proportions) was used. Quantitative data between two groups: IndependentSamples t-test was used if data were normally distributed in both groups. The non-parametric alternative Mann-Whitney $\mathrm{U}$ test was used if not. Multi-variable logistic regression: This analysis was used to create a prediction model of the likelihood of a diagnosis to detect the significant "independent" predictors with their OR (95\% CI). For any of the used tests, results were considered as statistically significant if $\mathrm{p}$ value $\leq 0.050$.

\section{Results}

The study included 120 patients (84 male and 36 female) aged 50-66 years. The patients were classified into 2 groups according to the presence or absence of early rebleeding; group 1 included 24 patients (20\%) with early rebleeding groups and the group 2 included 96 patients (80\%) without early rebleeding. According to early mortality the patients were divided into early mortality group included 19 patients $(15.8 \%)$ and patients roup without early mortality included $101(84.2 \%)$ patients.

(Table 1) shows that there was no statistically significant difference in age, sex, hepatic encephalopathy, presence of HCC and diabetes between the two study groups, but proportions of patients with current smoker, severe ascites and renal impairment, were significant higher in early rebleeding group. Moreover, there were no statistically significant differences between the study groups as regards, hemoglobin, RBCs, RBG, serum AST and serum ALT. While there were a statistically significant higher serum bilirubin, INR, serum creatinine, CTP and MELD scores and a statistically significantly lower serum albumin, and platelet count in those with early rebleeding.

(Table 2) shows that there were no statistically significant difference as regards, age, sex, presence of HCC and diabetes, between the two study groups. But current smoking hepatic encephalopathy, ascites, early rebleeding and renal impairment were significantly higher in early mortality group. Furthermore, here was no statistically significant difference between the two study groups as regards, platelet count, hemoglobin and RBCs. But there were a statistically significant higher serum bilirubin, INR, 


\section{Original Article}

serum creatinine, transaminases (AST and ALT) and patients with a higher CTP score and MELD scores and a statistically significant lower serum albumin in those with early mortality. (Table 3) shows that there were no statistically significant difference in gastric variceal signs as regard type, size, spurting, oozing, white nipple sign, cherry red spots, and number of varices in early rebleeding versus non rebleeding group. (Table 4) shows that there were significant increase in mortality in patients with more than one varix $(\mathrm{P}=0.045)$ while there were no statistically significant difference in gastric variceal signs as regard type, size, spurting, oozing, white nipple sign, cherry red spots, and PHG in early mortality versus non mortality group. (Table 5) showed logistic regression analysis which found that CTP score was statistically significant as independent predictor. For every one point increase in CTP score, patients had 1.45 times higher odds to exhibit early rebleeding. While renal impairment, MELD score and platelet count were not statistically significant. Also table (5) shows that, CTP score were statistically significant as independent predictor of early mortality. For every one point increase in CTP score, patients had 1.79 times higher odds to exhibit early mortality, while MELD score, early rebleeding, renal impairment, and platelet count were not statistically significant.

\section{Discussion}

In this study, the percentage of early rebleeding was $20 \%$. Another study verified that, the rebleeding rate following endoscopic injection of fundic varices was $16 \%$ 28 , however two other studies demonstrated a high rebleeding rates ranged from $29-35 \%{ }^{29,30}$.

By using logistic regression analysis we found that, CTP score was statistically significant as independent predictor for early rebleeding in patien with gastric variceas treated by cyanoacrylate glues, in addition, for every one point increase in CTP score, patients had 1.45 times higher odds to exhibit early rebleeding. However, MELD score, renal impairment and platelet count were not statistically significant as predictors for for early rebleeding. Another study demonstrated that, the deterioration of MELD and CTP scores are significantly predictive of mortality in cirrhotic patients with an acute $\mathrm{GVB}^{31}$.

Table 1. Demographic, clinical and laboratory parameters in the two study groups according to presence of early rebleeding:

\begin{tabular}{|c|c|c|c|}
\hline \multirow[b]{2}{*}{ Parameter } & \multicolumn{2}{|c|}{ Groups } & \multirow[b]{2}{*}{$\mathrm{P}$} \\
\hline & $\begin{array}{l}\text { Without early rebleeding } \\
\qquad(\mathrm{N}=96)\end{array}$ & $\begin{array}{l}\text { With early rebleeding } \\
\qquad(\mathrm{N}=\mathbf{2 4})\end{array}$ & \\
\hline Age (years) & Mean $\pm \mathrm{SD}=59.5 \pm 6.6$ & Mean $\pm \mathrm{SD}=56 \pm 6.9$ & $0.099 *$ \\
\hline $\begin{array}{l}\text { Sex:Male/Female } \\
(\mathrm{N} / \%)\end{array}$ & $66 / 30((68.75 / 31.25)$ & $18 / 6(75 \% / 25)$ & $0.550 * *$ \\
\hline Smoking: yes/ No & $74 / 22$ & $13 / 11$ & $0.031 * * * *$ \\
\hline HE: No/grade I-II & $86(89.6 \%) / 10(10.4 \%)$ & $18(75 \%) / 6(25 \%)$ & $0.088 * *$ \\
\hline $\begin{array}{l}\text { Ascites: } \\
\text { Absent/ present }\end{array}$ & $17 / 79$ & $2 / 122$ & $0.034 * * * *$ \\
\hline Renal impairment: & $4(4.1 \%)$ & $8(33.3 \%)$ & $<0.001 * * * *$ \\
\hline Presence of HCC & $15(15.6 \%)$ & $5(20.8 \%)$ & $0.547 * *$ \\
\hline Diabetes & $42(43.8 \%)$ & $7(29.2 \%)$ & $0.194 * *$ \\
\hline Bilirubin (mg/dl) & $1.25(0.9-2.7)$ & $5.05(2.8-12.5)$ & $<0.001 *$ \\
\hline Albumin (mg/dl) & $2.9(2.5-3.4)$ & $2.45(2.3-2.6)$ & $0.002 *$ \\
\hline INR & $1.3(1.2-1.7)$ & $1.5(1.3-1.9)$ & 0.028* \\
\hline Creatinine (mg/dl) & $0.8(0.8-0.9)$ & $1.1(0.9-2.2)$ & $<0.001 *$ \\
\hline Platelet(10^3/ul) & $160.5(118.5-254.75)$ & $122.5(84.75-200.25)$ & $0.022 *$ \\
\hline Hemoglobin (g/dl) & $9.15(7.7-9.8)$ & $9.05(8.4-9.5)$ & $0.616^{*}$ \\
\hline RBCs $\left(10^{\wedge} 6 / \mathrm{ul}\right)$ & $3.33 \pm 0.6$ & $3.1 \pm 0.7$ & $0.175^{* *}$ \\
\hline $\mathrm{RBG}(\mathrm{mg} / \mathrm{dl})$ & $155.5(120-247)$ & $152.5(117-178.75)$ & $0.522 *$ \\
\hline AST (mg/dl) & $37(25.25-56.25)$ & $55.5(24.25-83)$ & $0.138 *$ \\
\hline $\operatorname{ALT}(\mathrm{mg} / \mathrm{dl})$ & $28(21-40)$ & $48(20-68.75)$ & $0.097^{*}$ \\
\hline CTP class: $\mathrm{A} / \mathrm{B} / \mathrm{C}$ & $23(24 \%) / 53(55.2 \%) / 20(20.8 \%)$ & $2(8.3 \%) / 4(16.7 \%) / 18(75 \%)$ & $<0.001 * * *$ \\
\hline $\begin{array}{l}\text { MELD score: Median } \\
\text { (IQR) }\end{array}$ & $16.9(15.7-17.8)$ & $22.5(19.8-29.8)$ & $<0.001 *$ \\
\hline
\end{tabular}

Data are presented as count (\%) unless otherwise stated. *Independent-sample t-test $* *$ Chi-square test***Mann-Whitney U test, ****Fisher's exact test. 
Table 2. Demographic, clinical and laboratory parameters in the two study groups according to presence of early mortality:

\begin{tabular}{|c|c|c|c|}
\hline \multirow[b]{2}{*}{ Parameter } & \multicolumn{2}{|c|}{ Group } & \multirow[b]{2}{*}{$\mathrm{P}$} \\
\hline & $\begin{array}{l}\text { Without early mortality } \\
\qquad(\mathrm{n}=\mathbf{1 0 1})\end{array}$ & $\begin{array}{l}\text { With early mortality } \\
\qquad(\mathrm{n}=19)\end{array}$ & \\
\hline Age (years) & Mean $\pm \mathrm{SD}=58.3 \pm 6.8$ & Mean $\pm \mathrm{SD}=56.4 \pm 6$ & $0.243^{*}$ \\
\hline Sex: Male/Female (N/\%) & 70/31 (69.3/ 30.7) & $14 / 5(73.3 / 26.3)$ & $0.702 * * *$ \\
\hline Smoking: Yes/ No & $77 / 24$ & $10 / 9$ & $<0.001 * * * *$ \\
\hline HE: No/ grade I-II & $91(90.1 \%) / 10(9.9 \%)$ & $13(68.4 \%) / 6(31.6 \%)$ & $0.021 * * *$ \\
\hline Ascites: Absent/ present & $19 / 2359$ & $0 / 19$ & $0.002 * * * *$ \\
\hline Renal impairment & $5(5 \%)$ & $7(36.8 \%)$ & $<0.002 * * * *$ \\
\hline $\mathrm{HCC}$ & $14(13.9 \%)$ & $6(31.6 \%)$ & $0.088 * * * *$ \\
\hline Diabetes & $43(42.6 \%)$ & $6(31.6 \%)$ & $0.371 * * *$ \\
\hline Early rebleeding & $13(54.2 \%)$ & $11(45.8 \%)$ & $<0.001 * * *$ \\
\hline Serum bilirubin (mg/ dl) & $1.3(0.9-2.7)$ & $9(3.1-12.5)$ & $<0.001 *$ \\
\hline Serum albumin (mg/dl) & $2.97 \pm 0.66$ & $2.33 \pm 0.32$ & $<0.001 * *$ \\
\hline INR & $1.34(1.21-1.67)$ & $1.76(1.35-2.13)$ & $0.004 *$ \\
\hline Serum creatinine (mg/dl) & $0.9(0.8-1.0)$ & $1.3(0.9-2.9)$ & $<0.001 *$ \\
\hline Platelet $\left(10^{\wedge} 3 / \mathrm{ul}\right)$ & $159(117-242)$ & $139(87-253)$ & $0.412 *$ \\
\hline Hemoglobin (g/dl) & $9.2(8.0-9.8)$ & $8.9(7.7-9.5)$ & $0.515^{*}$ \\
\hline $\operatorname{RBCs}\left(10^{\wedge} 6 / \mathrm{ul}\right)$ & $3.31 \pm 0.68$ & $3.21 \pm 0.51$ & $0.534 * *$ \\
\hline RBG (mg/dl) & $155(120-246)$ & $153(142-220)$ & $0.735^{*}$ \\
\hline AST (mg/dl) & $36(24-52.5)$ & $64(40-111)$ & $0.004 *$ \\
\hline $\operatorname{ALT}(\mathrm{mg} / \mathrm{dl})$ & $27(19.5-40)$ & $62(32-160)$ & $<0.001 *$ \\
\hline CTP class: $\mathrm{A} / \mathrm{B} / \mathrm{C}$ & $\begin{array}{c}25(24.8 \%) / 54(53.5 \%) / 2 \\
(21.8 \%)\end{array}$ & $\begin{array}{c}0(0 \%) / 3(15.8 \%) / 16 \\
(84.2 \%)\end{array}$ & $<0.001 * * * *$ \\
\hline $\begin{array}{l}\text { MELD score: } \\
\text { Median(IQR) }\end{array}$ & $16.95(15.74-17.97)$ & $23.35(21.25-38.81)$ & $<0.001 * *$ \\
\hline
\end{tabular}

Data are presented as count $(\%)$ unless otherwise stated. *Independent-samples t-test, **Mann-Whitney U test, ***Chi-square test, ****Fisher's exact test.

Table 3. Endoscopic gastric variceal signs in the two study groups according to presence of early rebleeding:

\begin{tabular}{|c|c|c|c|c|}
\hline \multirow[b]{2}{*}{ Variable } & \multicolumn{2}{|c|}{ Groups } & \multirow[b]{2}{*}{$\chi^{2}$} & \multirow[b]{2}{*}{$\mathbf{P}$} \\
\hline & $\begin{array}{l}\text { With early rebleeding } \\
\qquad(\mathrm{n}=\mathbf{2 4})\end{array}$ & $\begin{array}{l}\text { Without early } \\
\text { rebleeding } \\
(\mathbf{n}=96)\end{array}$ & & \\
\hline \multicolumn{5}{|l|}{ Type of varices: } \\
\hline IGV & $2(8.3 \%)$ & $5(5.2 \%)$ & & \\
\hline GOV & $22(91.7 \%)$ & $86(89.6 \%)$ & 1.581 & \\
\hline GOV+IGV & $0(0 \%)$ & $5(5.2 \%)$ & & 0.454 \\
\hline \multicolumn{5}{|l|}{ Size of varices: } \\
\hline Small/Medium/Large & $8 / 5 / 11$ & $33 / 22 / 41$ & 0.086 & 0.958 \\
\hline Spurting: Yes/ No & $5(20.8 \%) / 19(79.2 \%)$ & $12(12.5 \%) / 84(87.5 \%)$ & 1.097 & 0.329 \\
\hline Oozing: Yes/ No & $1(4.2 \%) / 23(95.8 \%)$ & $19(19.8 \%) / 77(80.2 \%)$ & 3.375 & 0.073 \\
\hline WNS: Yes/ No & $3(12.5 \%) / 21(87.5 \%)$ & $11(11.5 \%) / 85(88.5 \%)$ & 0.020 & 1.000 \\
\hline CRS: Yes/ No & $4(16.7 \%) / 20(83.3 \%)$ & $9(9.4 \%) / 87(90.6 \%)$ & 1.057 & 0.304 \\
\hline varices: One/ > one & $19(79.2 \%) / 5(20.8 \%)$ & $76(79.2 \%) / 20(20.8 \%)$ & 0.379 & 0.827 \\
\hline
\end{tabular}

IGV, Isolated gatric Varicx; WNS, White nipple sign; CRS, Cherry red spots; Data are presented as count (\%) Chi-square test. 
Table 4. Endoscopic gastric variceal signs in the two study groups according to presence of early mortality:

\begin{tabular}{|c|c|c|c|c|}
\hline \multirow[b]{2}{*}{ Variable } & \multicolumn{2}{|c|}{ Groups } & \multirow[b]{2}{*}{$\chi^{2}$} & \multirow[b]{2}{*}{$\mathbf{P}$} \\
\hline & $\begin{array}{l}\text { With early mortality } \\
\qquad(\mathrm{n}=19)\end{array}$ & $\begin{array}{l}\text { Without early mortality } \\
\qquad(\mathrm{n}=\mathbf{1 0 1})\end{array}$ & & \\
\hline Type of varices: & & & & \\
\hline IGV & $0(0 \%)$ & $7(6.9 \%)$ & & \\
\hline GOV & $18(94.7 \%)$ & $90(89.1 \%)$ & 1.438 & 0.487 \\
\hline GOV+IGV & $1(5.3 \%)$ & $4(4.0 \%)$ & & \\
\hline $\begin{array}{l}\text { Size of varices: } \\
\text { Small/Medium/ } \\
\text { Large }\end{array}$ & $7 / 5 / 7$ & $34 / 22 / 45$ & 0.413 & 0.813 \\
\hline Spurting: Yes/No & $4(21.1 \%) / 15(78.9 \%)$ & $13(12.9 \%) / 88(87.1 \%)$ & 0,880 & 0.470 \\
\hline Oozing:Yes/ No & $1 / 18(94.7 \%)$ & $19(18.8 \%) / 82(81.2 \%)$ & 2.114 & 0.193 \\
\hline WNS:Yes/ No & $3(15.8 \%) / 16(84.2 \%)$ & $11(10.9 \%) / 90(89.1 \%)$ & 0.372 & 0.464 \\
\hline CRS:Yes/ No & $2(10.5 \%) / 17(89.5 \%)$ & $11(10.9 \% 5) / 90(89.1 \%)$ & 0.002 & 1.000 \\
\hline Varices: One/ > one & $11(57.9 \%) / 8(42.1 \%)$ & $84(83.2 \%) / 17(16.8 \%)$ & 6.198 & 0.045 \\
\hline
\end{tabular}

WNS, White nipple sign; CRS, Cherry red spots; Data are presented as count (\%) Chi-square test.

Table 5. Predictors of early rebleeding and mortality:

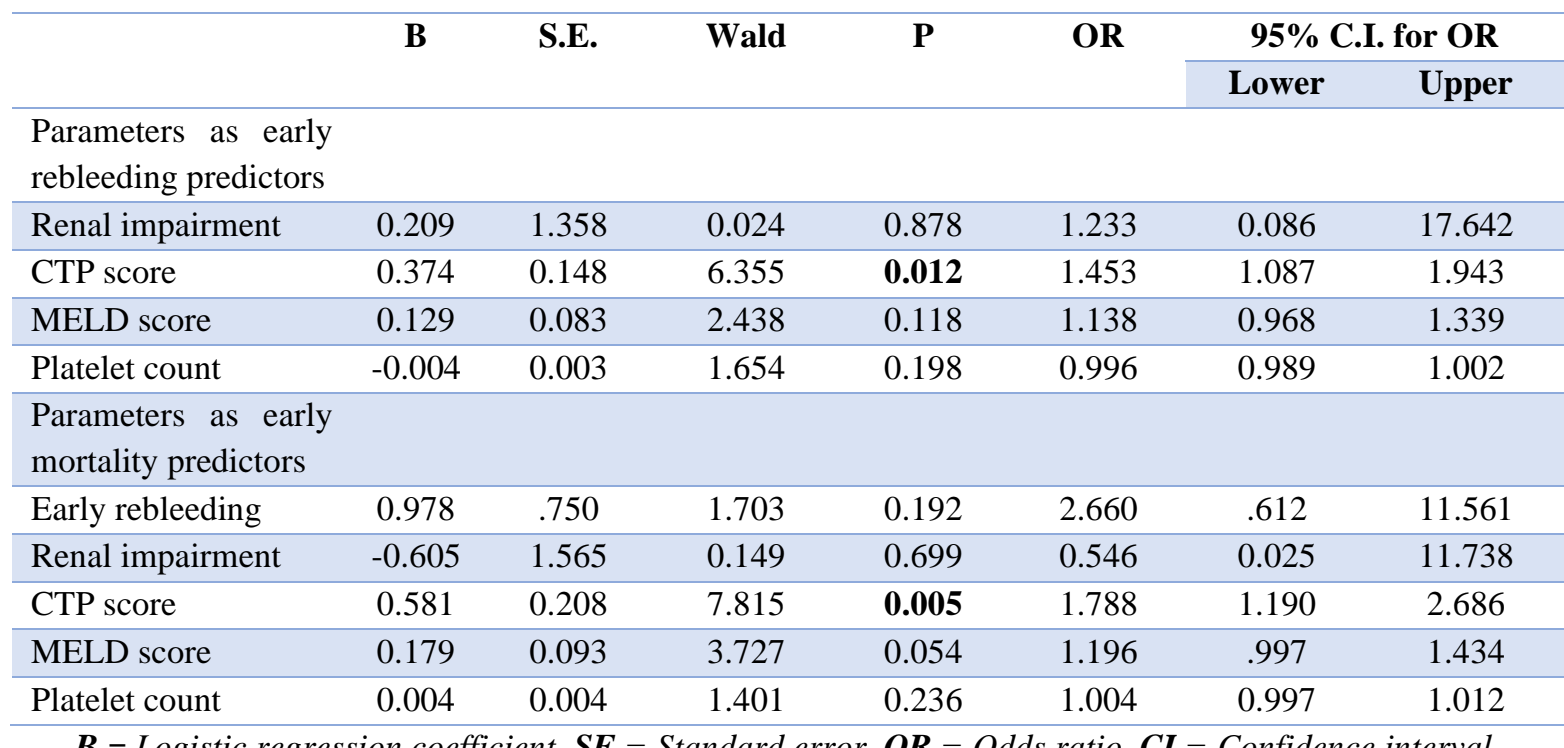

There was a statistically significant increase in ascites in early rebleeding group. This result is in accordance with Yoshida et al, who said that the presence of ascites was the only factor associated with both early and late rebleeding in patients with active gastric variceal hemorrhage treated by Histoacryl injection ${ }^{12}$. In our study, there was a statistically significant increase in renal impairment in early rebleeding group. This result was in concordance with the study, which found that lower renal function is associated with higher risk for rebleeding ${ }^{32}$. In our study, there was a statistically significant decrease in serum albumin and increase in INR in early rebleeding group. This result is in concordance with another study found that, a low albumin level was predictor of rebleeding in cirrhotic patients and coagulopathy may play role in rebleeding ${ }^{33}$. Although platelet count in this study is not a predictive factor for early rebleeding, there was a statistically significant decrease in platelet count in those with early rebleeding in comparision to patients without early rebleeding and this result is in concordance with previous studies ${ }^{33}$, 25. Similarly, we found that, there was a statistically significant higher MELD score in early rebleeding group but not documented as a predictive factor. On the other side, this result is in agreement with Liang et al, who said CTP score $\geq 9$ as well as MELD score $\geq 18$, are independent predictors of rebleeding in cirrhotic patients ${ }^{32}$. In our study, we found that, the type of GV and stigmata of initial endoscopy were not significant predictors of rebleeding and mortality. A similar result was reported in 
previous study by Marques et $\mathrm{al}^{34}$. In our study, we found that, the type of GV and stigmata of initial endoscopy were not significant predictors of re-bleeding and mortality. A similar result was reported in previous study by Marques et $\mathrm{al}^{34}$. While the Child-Pugh score (CTP) was predictive of early mortality, the MELD score, early rebleeding, renal impairment, and platelet count were not a significant predictive factors for early mortality. For every one point increase in CTP score, patients had 1.79 times higher odds to exhibit early mortality. This result is in agreement with some studies declared that, Child-Pugh score was predictors of re-bleeding and mortality in cirrhotic patients with gastric varices ${ }^{31,34}$. In group without early mortality, we found that, there was significant increase in serum bilirubin in early mortality group. This result is in concordance with, previous study found that, elevated total bilirubin level was significantly correlated with mortality ${ }^{10}$. Also, there was a significant increase in hepatic encephalopathy in an early mortality group versus patients without early mortality and this result is in agreement with another studies showed that, patients with encephalopathy were at high risk for shortterm death ${ }^{35,36}$. As regard ascites, we found that there was a significant increase in ascites in early mortality group. This result is in agreement with previous studies demonstrated that, the presence of ascites was a predictive of early mortality in patients with gastric varices ${ }^{18,37}$. This study declared that, there was a significant renal impairment in early mortality group in comparison to survival group. This result is in accordance with previous studies found that renal imparment was associated with increased mortality ${ }^{31}$. We found that, there was statistically significant decrease in serum albumin in early mortality group. This result is in accordance with $\mathbf{3 8}$ who said that low albumin was predictive factor associated with an increased mortality at 6 weeks. Although, this study found a non significant difference as regards HCC in early mortality groups versus nonmortility group, another studies found that, HCC was a predictor of short-term mortality after acute variceal bleeding ${ }^{39,40}$. There was a statistically significant increase in INR in those with early mortality. This result run parallel with ${ }^{41}$ who found that increase INR was independent prognostic factor of 6 weeks mortality. Furthermore, there was no statistically significant difference in platelet count in early mortality group versus non mortility group. This result differs from another study said that, low platelets count was predictors of early mortality ${ }^{25}$. We found that, there was a statistically significant increase in early mortality in those with early rebleeding compared to those without. This result is in agreement with Tega et al, who assumed that, rebleeding within 5 days plays a critical role in determining the predictor of mortality within 6 weeks after acute $\mathrm{GVB}^{31}$. However, some researcher assumed that late rebleeding were significantly correlated with mortality 10 .

\section{Conclusion}

The CTP score was highly significant independent predictor of early rebleeding, and mortality. The severity of liver disease represented by high CTP score rather than other factors including the endoscopic gastric variceal signs had significant influence on both early rebleeding and early mortality in cirrhotic patients with gastric variceal bleeding. So, cirrhotic patients with higher CTP should be monitored carefully after GVB because they have higher rebleeding and mortality rates.

\section{References}

1. Mousa, N., Abdel-Razik, A., Sheta, T., et al. (2021). Endoscopic management of acute oesophageal variceal bleeding within 12 hours of admission is superior to 12-24 hours. British Journal of Biomedical Science, 78(3), 130-134.

2. Garcia-Tsao, G., Abraldes, J. G., Berzigotti, A., et al. (2017). Portal hypertensive bleeding in cirrhosis: Risk stratification, diagnosis, and management: 2016 practice guidance by the American Association for the study of liver diseases. Hepatology, 65(1), 310-335.

3. Ibrahim, I., Elsaid, E., Dina, N., et al. (2020). Frequency and characterization of mixed ascites among cirrhotic patients admitted to Zagazig University hospital. Medical Journal of Viral Hepatitis, 4(2), 7580.

4. Mousa, N., Abdel-Razik, A., Sheta, T., et al. (2021). Endoscopic management of acute oesophageal variceal bleeding within 12 hours of admission is superior to 12-24 hours. British Journal of Biomedical Science, 78(3), 130-134.

5. Luketic, V. A., and Sanyal, A. J. (2000). Esophageal varices: I. Clinical presentation, medical therapy, and endoscopic therapy. Gastroenterology Clinics of North America, 29(2), 337-385.

6. Yoshida, H., Mamada, Y., Taniai, N., et al. (2006). New methods for the management of gastric varices. World Journal of Gastroenterology: WJG, 12(37), 5926.

7. de Franchis, R. (2010). Revising consensus in portal hypertension: report of the Baveno $\mathrm{V}$ consensus workshop on methodology of diagnosis and therapy in portal hypertension. Journal of hepatology, 53(4), 762768.

8. Sarin, S. K., Lahoti, D., Saxena, S. P., et al. (1992). Prevalence, classification and natural history of gastric varices: a long-term follow-up study in 568 portal hypertension patients. Hepatology, 16(6), 1343-1349.

9. Al-Osaimi, A. M., and Caldwell, S. H. (2011, September). Medical and endoscopic management of gastric varices. In Seminars in interventional radiology (Vol. 28, No. 03, pp. 273-282). (C) Thieme Medical Publishers.

10. Prachayakul, V., Aswakul, P., Chantarojanasiri, T., et al. (2013). Factors influencing clinical outcomes of Histoacryl® glue injection-treated gastric variceal hemorrhage. World Journal of Gastroenterology: WJG, 19(15), 2379. 
11. Sarin, S. K. (1997). Long-term follow-up of gastric variceal sclerotherapy: an eleven-year experience. Gastrointestinal endoscopy, 46(1), 8-14.

12. Yoshida, H., Mamada, Y., Taniai, N., et al. (2006). New methods for the management of gastric varices. World Journal of Gastroenterology: WJG, 12(37), 5926.

13. Mumtaz, K., Majid, S., Shah, H. A., et al. (2007). Prevalence of gastric varices and results of sclerotherapy with N-butyl 2 cyanoacrylate for controlling acute gastric variceal bleeding. World Journal of Gastroenterology: WJG, 13(8), 1247.

14. Lo, G. H., Lai, K. H., Cheng, J. S., et al. (2001). A prospective, randomized trial of butyl cyanoacrylate injection versus band ligation in the management of bleeding gastric varices. Hepatology,33(5), 10601064.

15. Zhao, J. R., Wang, G. C., Hu, J. H., et al. (2014). Risk factors for early rebleeding and mortality in acute variceal hemorrhage. World Journal of Gastroenterology: WJG, 20(47), 17941.

16. Matsumoto, A., Hamamoto, N., Nomura, T., et al. (1999). Balloon-occluded retrograde transvenous obliteration of high risk gastric fundal varices. The American journal of gastroenterology, 94(3), 643-649.

17. Tripathi, D., Ferguson, J. W., Therapondos, G., et al. (2006). Recent advances in the management of bleeding gastric varices. Alimentary pharmacology \& therapeutics, 24(1), 1-17.

18. Bambha, K., Kim, W. R., Pedersen, R., et al. (2008). Predictors of early re-bleeding and mortality after acute variceal haemorrhage in patients with cirrhosis. Gut, 57(6), 814-820.

19. Pashai, S. M., Ebrahimi, M., and Sheikhian, M. R. (2013). Comparison of Prognosis in Patients with Liver Cirrhosis and its Correlation with the Model for the End-Stage Liver Disease and Child-Pugh Scores in Patients with Esophageal or Gastric Variceal Bleeding. Galen Medical Journal, 2(3), 106-113.

20. Hunter, S. S., and Hamdy, S. (2013). Predictors of early re-bleeding and mortality after acute variceal haemorrhage. Arab Journal of Gastroenterology, 14(2), 63-67.

21. Child, C.G., Turcotte, J.G. (1964). Surgery and portal hypertension. In child CG, editor: The liver and portal hypertension. Philadelphia, W.B. Saunders Co., 50.

22. Boone, M. D., Celi, L. A., Ho, B. G., et al. (2014). Model for End-Stage Liver Disease score predicts mortality in critically ill cirrhotic patients. Journal of critical care, 29(5), 881-e7.

23. Kim, T., Shijo, H., Kokawa, H., et al. (1997). Risk factors for hemorrhage from gastric fundal varices. Hepatology, 25(2), 307-312.

24. Tan, P. C., Hou, M. C., Lin, H. C., et al. (2006). A randomized trial of endoscopic treatment of acute gastric variceal hemorrhage: N-butyl-2-cyanoacrylate injection versus band ligation. Hepatology, 43(4), 690697.
25. Charif, I., Saada, K., Mellouki, I., et al. (2013). Predictors of early rebleeding and mortality after acute variceal hemorrhage in patients with cirrhosis. Open Journal of Gastroenterology, 3:(6), 317-321

26. Krige, J.E.J., Kotze, U.K., Distiller, G., et al. (2009). Predictive Factors for Rebleeding and Death in Alcoholic Cirrhotic Patients with Acute Variceal Bleeding: A Multivariate Analysis. World Journal of Surgery, 33(10), 2127-2135.

27. Yeung, E., Yong, E., and Wong, F. (2004). Renal dysfunction in cirrhosis: diagnosis, treatment, and prevention. Medscape General Medicine, 6(4).

28. Rajoriya, N., Forrest, E. H., Gray, J., et al. (2011). Long-term follow-up of endoscopic Histoacryl glue injection for the management of gastric variceal bleeding. QJM: An International Journal of Medicine, 104(1), 41-47.

29. Joo, H. S., Jang, J. Y., Eun, S. H., et al. (2007). Longterm results of endoscopic histoacryl (N-butyl-2cyanoacrylate) injection for treatment of gastric varices--a 10-year experience. The Korean journal of gastroenterology $=$ Taehan Sohwagi Hakhoe chi, 49(5), 320-326.

30. Akahoshi, T., Hashizume, M., Shimabukuro, R., et al. (2002). Long-term results of endoscopic Histoacryl injection sclerotherapy for gastric variceal bleeding: a 10-year experience. Surgery, 131(1), S176-S181.

31. Teng, W., Chen, W. T., Ho, Y. P., et al. (2014). Predictors of mortality within 6 weeks after treatment of gastric variceal bleeding in cirrhotic patients. Medicine, 93(29).

32. Liang, C. C., Chou, C. Y., Chang, C. T., et al. (2016). Upper gastrointestinal bleeding as a risk factor for dialysis and all-cause mortality: a cohort study of chronic kidney disease patients in Taiwan. BMJ open, 6(5), e010439.

33. Bosch, J., Berzigotti, A., Garcia-Pagan, J. C., et al. (2008). The management of portal hypertension: rational basis, available treatments and future options. Journal of hepatology, 48, S68-S92.

34. Marques, P., Maluf-Filho, F., Kumar, A., et al. (2008). Long-term outcomes of acute gastric variceal bleeding in 48 patients following treatment with cyanoacrylate. Digestive diseases and sciences, 53(2), 544-550.

35. Wlodzimirow, K., Abu-Hanna, A., and Chamuleau, R. A. (2013). Acute-on-chronic liver failure-its definition remains unclear. Journal of hepatology, 59(1), 190191.

36. Jalan, R., Gines, P., Olson, J. C., et al. (2012). Acuteon chronic liver failure. Journal of hepatology, 57(6), 1336-1348.

37. Hassanien, M., EL-Talkhawy, M.D., Maged, E-G., et al. (2015). Predictors of In-Hospital Mortality in patients with hepatocellular carcinoma and Acute Variceal bleeding. Electronic physician, 7(6), 1336.

38. Lo, G.H., Chen, W.C., Chen, M.H., et al. (2004). Endoscopic ligation VS. Nadolol in the prevention of 
first variceal bleeding in patients with cirrhosis. Gastrointestinal endoscopy, 59(3), 333-338.

39. Han, M. L., Chen, C. C., Kuo, S. H., et al. (2014). Predictors of in-hospital mortality after acute variceal bleeding in patients with hepatocellular carcinoma and concurrent main portal vein thrombosis. Journal of gastroenterology and hepatology, 29(2), 344-351.

40. Komori, K., Kubokawa, M., Ihara, E., Akahoshi, K., Nakamura, K., Motomura, K., and Masumoto, A. (2017). Prognostic factors associated with mortality in patients with gastric fundal variceal bleeding. World journal of gastroenterology, 23(3), 496.

41. Lee, H. H., Park, J. M., Han, S., et al. (2018). A simplified prognostic model to predict mortality in patients with acute variceal bleeding. Digestive and Liver Disease, 50(3), 247-253. 